\title{
Going out on a Limb: Prosthetics, Normalcy and Disputing the Therapy/Enhancement Distinction
}

Isabel Karpin

Roxanne Mykitiuk

Osgoode Hall Law School of York University, rmykitiuk@osgoode.yorku.ca

Source Publication:

Medical Law Review 16:3 (2008), p. 413-436

Follow this and additional works at: https://digitalcommons.osgoode.yorku.ca/scholarly_works

\section{Recommended Citation}

Karpin, Isabel, and Roxanne Mykitiuk. "Going out on a Limb: Prosthetics, Normalcy and Disputing the Therapy/Enhancement Distinction." Medical Law Review 16.3 (2008): 413-436.

This Article is brought to you for free and open access by the Faculty Scholarship at Osgoode Digital Commons. It has been accepted for inclusion in Articles \& Book Chapters by an authorized administrator of Osgoode Digital Commons. 


\section{GOING OUT ON A LIMB: PROSTHETICS, NORMALCY AND DISPUTING THE THERAPY/ ENHANCEMENT DISTINCTION}

ISABEL KARPIN AND ROXANNE MYKITIUK*

\section{INTRODUCTION}

The development of genetic technologies, nano-technologies and technologies related to artificial intelligence have provoked discussion about the different uses to which they may be put; namely, their potential for therapeutic and non-therapeutic use. Resisting claims that individuals should be free to use these technologies as they see fit to alter their own physical, psychological and intellectual capacities, lifespan and morphologies or those of their existing or future children, some authors contend that both ethical and regulatory limits should be placed on this exercise of free choice. ${ }^{1}$ A number of academics have suggested that the therapy/enhancement distinction can perform both moral and regulatory work in assisting us with resolving the tricky issue of which uses of these technologies to permit and which to discourage or ban. $^{2}$ In this article, we examine how therapy and enhancement are characteristically understood in ethical, medical and legal contexts, and how these understandings rely on unstated assumptions about the meanings attributed to different forms of embodiment: normal and 
disabled, healthy and diseased, able-bodied and impaired, and beautiful and functional. We argue, consistent with feminist and disability studies critiques, that the idea of a 'normal' body as a benchmark against which other bodies are judged is unsustainable despite observing that 'the closer corporeality approximates to a socio-culturally variant position of normativity the more acceptable it becomes' ${ }^{3}$ We track the way in which bodies (within medico-legal and biotechnological discourses) are regulated and managed in relation to shifting normative ideals. This exploration leads us to conclude that the therapy/enhancement distinction is inadequate and unhelpful to guide ethical analysis and medical and regulatory decision making, and cannot adequately assist us in adjudicating when it is appropriate to allow individual choice and autonomy to govern the use of these technologies and when the State should intervene.

In the first part of this article, we critically examine the meaning of enhancement and therapy and draw on feminist and disability studies critiques of normalcy to put pressure on the viability of the distinction. Conventionally, therapeutic interventions are understood to restore or bring an individual' $\mathrm{s}$ morphology and capacities within the normal range, while enhancements imply going beyond that which is normal. The concept of 'normal' embodiment is the fulcrum upon which the therapy/enhancement distinction rests and from which it derives its purchase. Moreover, normatively, the idea of 'normal' or 'normalcy' 
sets the standard around which bodies are evaluated, regulated and are even permitted to materialise. However, as we argue below, what is 'normal' is 'not only being superceded in practice, but has been unstable all along' 4 and is thus unable to support the therapy/enhancement distinction that rests upon it. While exposing the fallacy of normalcy, we also come to understand that enhancement is a paradox. In its promise of something better, it renders those of us at the base line in a state of inadequacy.

Next, we focus on the idea of prosthesis as offering restoration and also as an 'add-on' . It is the perfect vehicle for deeper exploration of the therapy/enhancement distinction because restoration can never be complete if an add-on is always available to make us better. Using prosthesis as a model, we suggest that the 'normal' body is a theoretical construct dependent upon social and historical contexts.

Finally, using the example of the regulation of preimplantation genetic diagnosis (PGD), we demonstrate how laws that prohibit or limit the use of PGD for enhancement purposes and facilitate therapeutic uses of the technology cannot be characterised nor justified on the basis of this distinction. Legal rules based on ideas of 'normal' embodiment are, in fact, normative, constructing both a departure from and congruence with ideas about the normal/normative. In so doing, certain types of embodiment are elevated as self-evidently desirable while other forms of embodiment, what we might call anomalous, deviant or even disabled, are made 
preemptively undesirable. $^{5}$

\section{THERAPY, ENHANCEMENT AND NORMALCY}

\section{A. What Is Enhancement and What Is Therapy?}

In 2003, the US President' s Council on Bioethics examined the therapy/enhancement distinction in its report Beyond Therapy: Biotechnology and the Pursuit of Happiness. ${ }^{6}$ In a description offered (but in fact not explicitly relied upon by the Council), we are told that therapy understood in the context of the therapy/enhancement, distinction, and:

as in common understanding, is the use of biotechnical power to treat individuals with known diseases, disabilities, or impairments in an attempt to restore them to a normal state of health and fitness. ${ }^{7}$

Enhancement is described as:

the directed use of biotechnical power to alter, by direct intervention, not disease processes but the 'normal' workings of the human body and psyche, to augment or improve their native capacities and performances. $^{8}$

The report goes on to state:

Those who introduced this distinction hoped by this means to distinguish between the acceptable and the dubious or unacceptable uses of biomedical technology: therapy is always ethically fine, enhancement is, at least prima facie, ethically 
suspect. $^{9}$

However, the term enhancement is highly problematic. Does it mean 'more' or 'better' and, if 'better' , by what standards? If 'enhancement' is defined in opposition to 'therapy', whatdo 'healthy' and 'impaired' , 'diseased' , 'disabled' , 'normal' and 'abnormal' and 'super-normal' all mean? And what about the meaning of 'therapy' or 'treatment' ? Does it mean preserving or restoring someone to a standard of species typical normal functioning as is often suggested, ${ }^{10}$ and if so, can the norm be equated with the average? As the President' s Council asks: '[i]s it therapy to give growth hormone to a genetic dwarf, but not to a short fellow who is just unhappy to be short?' 11 Moreover, does treatment include aesthetic modifications and if so to what extent? ${ }^{12}$ Must such modification be limited to 'normalisation' rather than beautification? Does therapy include modification for the purposes of adjusting the body to suit the social environment whether or not that has the outcome of species typicality? The use of high-tech prostheses by double amputees that enable them to run fast is an example of this kind of intervention. We will return to this example below.

As Kerry Taylor and Roxanne Mykitiuk have written:

The 'normal' is perceived to be an objective way to think about human beings, a means to represent or quantify 'what is' on the basis of statistical averages. However, the 'normal' also contains 
often opaque and unquestioned value judgments, and is used to represent what is right, and desirable. [...] 'Normalcy' is used to rationalize medical attempts to eradicate our differences, and to render all bodies alike - healthy and interchangeable - as sameness is perceived to be the foundation of equality. ${ }^{13}$

The effect of this is to secure the social positioning of the disabled as abnormal and deviant rather than simply different. ${ }^{14}$ Scully and Rehmann-Sutter suggest that this exclusion from the normal may also result in a classification that places the person 'outside the category of being naturally human' $\quad \cdot{ }^{15}$ However, as we discuss below, the categories 'normal' and 'disabled' are problematised and confounded when having a disability is simultaneously construed as enabling or giving effect to a 'superability' . Parents of children with autism or Williams Syndrome, for instance, have argued that their children have both extraordinary capacities and incapacities at the same time. ${ }^{16}$

The therapy/enhancement distinction is clearly problematic. The concept of enhancement pre-supposes too many certainties about the so-called normal state beyond which it would or should be wrong to journey, while the concept of therapy embraces a standard of health and embodiedness that insists that those who do not meet it should desire to meet it, and need to meet it. The underlying assumption built into the therapy/enhancement distinction, that there are universal ideas of acceptable or desirable embodiment that must be interrogated. In order to challenge claims about what is and is not normative 
embodiment for the purposes of legitimating treatment or proscribing enhancement, we focus specifically on how understandings of disability and anomalous embodiment ${ }^{17}$ complicate the very basis of the distinction. Our aim here is to wrestle with assertions about what constitutes a deficiency and what constitutes an improvement.

\section{B. How Does the Therapy/Enhancement Distinction Guide}

\section{Ethical Analysis?}

In his article 'NBIC, NGO' $\mathrm{s}$ and the three types of disabled people' ${ }^{18}$ Gregor Wolbring describes three categories of disabled people. The first is the patient type who wishes to be fixed to the norm and sees his or her own biological reality as a defect, for whom medical care, rehabilitation and technological devices-including assistive or prosthetic devices - offer a fix towards or up to the norm. The second is the transhumanist ${ }^{19}$ type who 'sees their own body, as well as the 'normal' human body as a 'defect' in need of not just fixing to the norm but in need of augmentations above the norm with the addition of new abilities' facilitated by the use of new technologies. ${ }^{20}$ Finally, there is the social justice type who uses technology to change the physical environment or to change the interaction with the physical environment. In this model:

[d]isability is not seen as an attribute of an individual, but rather a complex collection of conditions, many of which are created by the 
[social] environment.. . and socially mediated aspects of the physical environment...[This] model of disability does not negate that a disabled person has a certain biological reality (like having no legs), which makes her/him different in her/his abilities, which make her/him not fit the norm. But it views the 'need to fit a norm' as the disability and questions whether many deviations from the norm need a medical solution (adherence to the norm) or a social solution (change/elimination of norm) ${ }^{21}$

While Wolbring has separated out those who seek to adjust their embodiment in line with technological opportunities from those who challenge the need to fit the norm, we suggest that the line between these categories is, in fact, fluid. For instance, one might want both prosthetic devices and alterations to the social environment. It is quite possible that an individual' sdesire to use prosthetics has nothing to do with fixing a 'defect' in his or her body and nothing to do with enhancement beyond the 'norm', but is rather about facilitating another way of being in the world. Recent scholarly debates about prosthetics are useful in helping us better understand the dynamics among the body, disability and technology and their relationship to normative evaluations about therapy and enhancement. By using the example of prosthesis, we show how regulation that is based on the possibility of a complete self towards which we might strive and beyond which we should not wish 
to go, fails to understand the prosthetic nature of all embodiment. If embodiment is always variable, then we need to come up with different ethical and legal justifications for regulating some uses of technologies and not others.

\section{PROSTHESIS, DISABILITY AND SUPER-ABILITY}

\section{A. Prosthetising the Body}

Disability scholars Mitchell and Snyder state that 'a body deemed lacking, unfunctional, or inappropriately functional needs compensation, and prosthesis helps to effect this end' ${ }^{22}$ Understood in this way, prosthesis is an addition or supplement to the bodyone that aims to restore wholeness to a body that is otherwise incomplete and abnormal. Prosthetics replace, or fill in for, something that is missing, and in their presence remind us of what is absent from that body. ${ }^{23}$ Through the use of prosthetics, an attempt is made to normalise the individual and deviant body so that, to the extent possible, it functions and looks like a 'normal' body.

However, Lennard Davis argues that the conceptualisation of the body as deficient does not necessitate its improvement. Rather, according to Davis, there is always and only a 'partial, incomplete subject whose realization is not autonomy and independence but dependency and interdependence'.$^{24}$ Davis suggests that a normal body is a theoretical construct and not a material reality. The norm is an 
idealised quantitative and qualitative measure that is divorced from (rather than derived from) the observation of bodies, which are inherently variable. Moreover, as Wills contends, 'the prosthetic body will not be an exception but the paradigm for the body itself' ${ }^{25}$ as we all attempt to shape, modify and contort our material flesh and blood bodies to fit the theoretical and idealised norm. But, the norm itself is not static, nor are the quantitative and qualitative dimensions used to establish the norm. That which is theoretical, abstract and idealised (the norm as opposed to the material body) is a shifting baseline around which distinctions about therapy and enhancement in relation to material bodies are made. As none of us has a normative body (one that corresponds to a 'universalised template of how corporeality should appear' $),{ }^{26}$ it is necessary to critique the standard of normalcy situating it within a shifting social and historical context where the meanings of bodies both in their material and conceptual form are constantly refigured. As Margrit Shildrick suggests:

[t]he claim that there might be a body, any body, that is not modified is surely implausible. Bodies are not static givens, nor do they settle, but rather emerge in both continuous and discontinuous process. ${ }^{27}$

Nevertheless, she agrees that there is the 'force of socio-cultural and psychic investments in promoting a universalised template of how corporeality should appear' ${ }^{28}$ 
The idea of the prosthetic is particularly useful here if we consider it not only in its conventional sense of replacing or restoring that which is missing, but as a means to facilitate ways of being that can be more or less in accordance with social norms and conventions. Returning to Wolbring' s typology of the relationship between disabled persons and technology, in our view, both the patient and transhumanist types illustrate the contradictions and contingencies of the regime of normalcy as individuals seek to modify themselves with and through technology in line with a base line that is itself constantly shifting over time as individuals continuously strive to achieve or surpass it. While Wolbring seems to suggest that only uses of technology that alter the physical environment and not the person can offer an antidote to the oppressive practices of normalising (and enhancing), we question whether (all) uses of prosthetic technology must be viewed as enforcing normalcy. Rather, consistent with the social model of disability, a critique of the therapy/ enhancement distinction would suggest that not all uses of prosthetics are aimed at modelling the body in accordance with the norm or normative body. If the appropriate response to disability resides in altering the environment writ large, and eliminating oppression on the basis of difference, then a technological/prosthetic alteration of the body, in a social context where such environmental alterations are also made, need not constitute therapy or enhancement.

Davis observes 'what is universal in life if there are universals, is the 
experience of the limitations of the body' ${ }^{29}$ We are all incomplete and disabled, requiring technological alterations and interventions to our environments and ourselves, and involvement by way of social policies and regulations to enable us. Unlike the transhumanist dystopia imagined by Wolbring, whereby the incomplete body is always regarded as negative and in need of improvement, Davis' incomplete subject is the ideal subject and the complete subject an unattainable fantasy that does harm to our sense of self. That being the case, prosthesis becomes one of a panoply of options that facilitates being in a body and being in a world, along with social and legal interventions which determine where value lies and the conditions within which what is valued can be distributed. Using the example of prosthesis both in its material and metaphorical sense, we suggest that what is problematic is not the possibility of bodily modification, but the policing through regulatory regimes of a normative embodiment that reflects some kind of average human functioning or that accords with specific oppressive ideals about appropriate aesthetic and physical manifestations and expressions.

Wolbring describes, by way of example, several ways to think of a person without legs rather than as disabled:

Let' stake a look at a - so called - 'disabled person' without legs. If he/she sees him/herself as a defect in need of legs he/she sees him/herself as a - so called - medical problem in need of fixing. 
Furthermore if he/she sees the concept of legs as they are as outdated and deficient and therefore tries to add on mobility devices to their body which makes him/her much more capable in his/her mobility than mere biological legs could provide with that self-understanding this person will of course support everyone and everything offering him/her this augmentation. However what if that person sees themselves as just fine in his/her biological reality and their different mode of movement? What if that person wants to have a societal cure meaning the fixing of society meaning that society starts to support their way of movement (wheelchair, crawling...)? $?^{30}$

Wolbring' s rereading of physical anomaly as something other than disability requires a further rethinking of not just disability but enhancement too. In Wolbring' s account of the ways to think about a person without legs, he includes the transhumanist model that he has outlined earlier. It is worth considering Wolbring' s decision to use the language of "transhumanism" in his analysis since we would argue that the kind of transhumanists to whom he refers wrongly presuppose a stable state of the human and human embodiment that have come before. ${ }^{31}$ The perception that one' $\mathrm{s}$ limbs are outdated and deficient because they are 'mere biological legs' suggests that the starting point for an analysis of treatment versus enhancement is constantly shifting and depends very much on the way in which the body is 
constructed. Contemporary enhancement technologies, in the transhumanist model, are described as allowing us to be more than, or beyond, human. ${ }^{32}$ However, if we view the human state as always incomplete then technologies that might be attached to the human can be understood as part of a panoply of social goods and ills that we might have access to and that need to be distributed justly or not at all. This is not to suggest that technological alterations to the body should be preferred over those made to the geographical and social environments, but that we must not concede the meaning of such bodily alterations to those sympathetic to transhumanist ideology.

\section{B. Proselytising Prosthetics?}

Histories of disability reveal the way in which attitudes towards people with, and the meanings ascribed to, anomalous bodies are contingent on broader cultural, economic and social factors. When we are forced to confront the positive alignment of anomalous embodiment with achievement and when this is done not by rendering the anomalies invisible but rather by emphasising their existence, the undesirability of that difference is profoundly challenged. It is not simply that this results in a sympathetic response to anomalous embodiment but more radically that it subverts the account of anomalies as disabling. Indeed, in some instances, disability has been recast as enhancement. This is not to question the very material and real consequences of 
living with a disability in a world that is not organised around that bodily difference, but to question the notion that in supplementing the aberrant body, the aim of prosthetics qua prosthetics is to keep the individual within the 'normal' range.

Rosemarie Garland-Thomson scrutinises 'the intersections between the politics of appearance and the medicalisation of subjugated bodies' ${ }^{33}$ in order to unpack the categories of disability and normalcy. She provides a schema of disability with four aspects:

[f]irst, it is a system for interpreting and disciplining bodily variations; second, it is a relationship between bodies and their environments; third it is a set of practices that produce both the able-bodied and the disabled; fourth it is a way of describing the inherent instability of the embodied self. ${ }^{34}$

Each of these form part of a system in which the 'fantasy of the body as a neutral, compliant instrument of some transcendent will' ${ }^{35}$ is radically challenged. Returning to the problematic of the prosthesis, it is Garland-Thomson' s account of the work of fashion model, elite athlete and double-amputee Aimee Mullins that is most illustrative for our purposes. Garland-Thomson argues that the juxtaposition of Mullins' s disabled body with the discourse of fashion represents an irruptive moment where 'as legless and beautiful she is an embodied paradox asserting an inherently disruptive potential' ${ }^{36}$ Born without fibulae, Mullins' parents made the decision to have her legs amputated 
below the knee when she was a baby and by doing so, to enable mobility through prosthetic limbs. Mullins uses a variety of prosthetic legs depending on the context. For instance, for fashion shoots she wears legs like those of a Barbie doll, not only long and slender, but fixed in a position to wear high heels. As an elite runner and when competing in races, Mullins wears titanium legs that are specially designed for this purpose. These legs, based on cheetah legs, bear little resemblance to natural human legs. As Garland-Thomson argues, the spectacularisation of disability in such contexts subverts normative responses to disability as disabling. This is not to suggest that corporeal variation is fabricated, but rather that the meaning of that variation is contingent upon culturally produced systems of understanding of the self.

Garland-Thomson describes the case of disabled fashion modelling as an activist cultural practice that is potentially transformative because the body on display is marked by a highly visible disability. Taking the first of Garland-Thomson' s four aspects of disability, rather than disciplining bodily variations in this instance, disability invokes an inherently disruptive potential that enables disability to be read as fashion. Aimee Mullins has posed in her running legs and her cosmetic legs for fashion houses such as Gucci and fashion magazines such as Dazed and Confused. While Garland-Thomson is impressed by Mullins' $s$ refusal to cover up or smooth over the joints where her artificial legs meet her flesh, and cites their 
appearance as a disruptive moment, there is, of course, a sense in which what is being referenced is the already existing and sexist requirement that women live up to ideals of beauty that are only realisable in plastic. Indeed, the reference to the doll or the mannequin is quite deliberate. This then draws out the second aspect of Garland-Thomson' s schema, the relationship between bodies and their environments. Mullins operates within the discourse of contemporary values and social oppressions. Marquard Smith argues, for instance, that Mullins is 'sexualized as an able-bodied woman who just happens to be an amputee'.${ }^{37}$ He goes on: ' 'a a]t best her status as an amputee must be acknowledged and disavowed simultaneously'.$^{38}$ While these discourses of sexist objectification do permeate the Mullins photo shoot, at the same time the representation of disability as undesirable or needing repair is challenged. Mullins' s more recent appearance in glass legs for the final episode of the movie Cremaster by Matthew Barney is a further play with the idea of prosthesis. These legs simultaneously fill the gap where her 'real' legs would be (making her whole) while in their transparency, exposing that very absence. ${ }^{39}$

In an advertisement for a UK internet company 'Freeserve' featuring Aimee Mullins as a fashion model on the catwalk, the relationship between normalcy, disability, bodily modification and enhancement is further interrogated in the narrative frame of an able-bodied young girl (approximately 8 years old). The advertisement begins with the 
little girl on the catwalk asking: 'What do I like about Aimee? Let' s see. She likes to run, like me. There is a lot of things that we have in common'. These words are interspersed with images of behind the scene preparations for the fashion show that include a parade of weird and fantastical characters. Aimee Mullins parades down the catwalk in runners, her cosmetic legs and finally her athletic legs. The advertisement ends with the little girl and Aimee sitting on the catwalk after the show in conversation. The girl turns to Mullins and says 'I mean you' re free to be who you want to be' to which Aimee nods. The final shot of the advertisement-first a view of Mullins from the waist down sitting in a chair, wearing her cheetah legs, then a shot of her face has Aimee saying 'it' s a total feeling of accomplishment' before fading to black and projecting the company' s name. Through this advertisement we see a complete inversion of normalcy and accomplishment. It starts with the little girl insisting on her commonality with Aimee and ends by insisting on difference as a state of accomplishment and freedom. The shocking suggestion that this able-bodied girl might indeed want to be Aimee Mullins, amputations and all, is inevitable and in this way our notions of what it is to be disabled and what it is to be enhanced are thrown into radical doubt. Indeed, the advertisement reverses the typical liberal humanist response of pity and worthy regard and borrows, instead, from discourses of triumphalism and heroism; because it neither fully occupies either discourse, it troubles both. While much of the 
material experience of embodiment by both the so-called abled and disabled is of the order of the everyday; going to the shops, doing a job, hanging out with friends and does not involve being a super model or running in the Olympics, the power of these subversive representational discourses and their mainstream validation by consumer capital cannot be underestimated. They force recognition of a spectrum of difference and variation rather than a binary between abled and disabled which is key to our challenge to the enhancement/ therapy distinction. Vivian Sobchack has described her experience of having a prosthetic leg in just these terms. She says:

Here with Aimee Mullins' s legs (both onscreen and off), we have both - and simultaneously - incorporation and projection, an overcoming and a resistance, an unstoppable 'difference' that is not about negation but about the alterity of becoming....As for me, despite my awe and admiration for Mullins... .I have no desire to keep pace with her... all [I want is] to be able to walk to work, to the store and maybe on a treadmill at the gym... so I can get about my world with the minimum of prosthetic thought. $^{40}$

What then is the 'normal' body from which all enhancements and therapies are to be benchmarked? Garland-Thomson argues that the so-called 'natural' body-that which is unmodified by medical intervention in this modern day consumerist universe - is no longer the 
normal body but rather the modified body is portrayed as normal in its most ideal state. Referring to cosmetic surgery, she says:

The beautiful woman of the twenty-first century is sculpted from top to bottom, generically neutral, all irregularities regularised, all particularities expunged. She is thus nondisabled, deracialised and de-ethnicised. ${ }^{41}$

We need to be careful here, however, to distinguish beauty from normalcy. The beautiful woman to whom Garland-Thomson refers is one who has been regularised or normalised. Standards of beauty as ideal, however, are typically not regular nor normal. Supermodels such as Kate Moss, Sophie Dahl, Gemma Ward and Agyness Deyn, to name a few, are not ordinary or regular by any stretch of the imagination. Gemma Ward, for instance, has been described as alien in appearance. ${ }^{42}$ Normative embodiment, created through cosmetic body modification practices, takes the place of 'natural' embodiment by allowing more people to access the same point on the bell curve. ${ }^{43}$ This demonstrates Garland-Thomson' $\mathrm{s}$ third (and perhaps most important for our purposes) aspect of disability, i.e. it is social practices that construct abled and disabled embodiment. These social practices also construct ideas of super-ability and enhancement. Sports enhancement is a potent example of how the desire to alter human biology is inextricably tied to existing social structures. Arguably, athletic excellence only takes on meaning in a field with 
definite rules and measurable standards. ${ }^{44}$ Oscar Pistorius, a doubleamputee sprinter, demonstrates this argument. Pistorius argued recently before the International Olympic Committee that he should be eligible to compete in the able-bodied Olympics using his prosthetic limbs. Initially, Pistorius' s request was denied. It was argued that his prosthetic limbs would give him an unfair advantage over runners competing with non-prosthetic legs. Rather than bring him up to the norm, it was suggested that Pistorius' $\mathrm{s}$ prosthetic legs would enhance his capacity to run. The prosthetic legs, it is argued, make him taller and give him a longer stride than he would have had with his natural legs, thereby giving him an unfair advantage when using them to compete against those without such prosthetics. As Jeré Longman of the New York Times described:

Pistorius wants to be the first amputee runner to compete in the Olympics. But despite his ascendance, he is facing resistance from track and field' s world governing body, which is seeking to bar him on the grounds that the technology of his prosthetics may give him an unfair advantage over sprinters using their natural legs. ${ }^{45}$

In 2007, the International Association of Athletics Federations (IAAF) prohibited the use of 'any technical device that incorporates springs, wheels or any other element that provides a user with an advantage over another athlete not using such a device' ${ }^{46}$ It was thought that this 
would exclude runners such as Pistorius from competing with the socalled able-bodied athletes. ${ }^{47}$ In May 2008, however, the Court of Arbitration for Sport ruled that there was insufficient evidence to prove that Pistorius' flexible prosthetic legs gave him an advantage. ${ }^{48}$ But the issue is not just one of advantage but of an 'unfair' advantage. Critiques of enhancement aids in the context of athletic performance typically rely upon two claims: first, that achievement has not been earned and secondly, that the use of aids is unfair because not all athletes have equal access to them. ${ }^{49}$ But, can these arguments be sustained in the case of Oscar Pistorius? Is the benefit he gets from his prosthetic legs an unearned advantage? The argument about equal access to prosthetic legs is alarming in its implications - that other runners should remove their 'natural' legs and don prosthetic legs like his in order to compete with him. But, short of this, what can Pistorius do? While other sprinters can experiment with high-tech shoes, and wear friction-free fibre, utilise computer-aided training techniques, imbibe nutritional supplements, and work out highly technical chemically balanced diets, it seems highly questionable to position the fault line between the acceptable and the unacceptable at Oscar' $s$ legs. Here, we see the concept of enhancement failing to adequately manage the complex relation between the contemporary highly technologised and always already modified but so-called 'natural' body and the enhanced/modified socalled disabled body. ${ }^{50}$ 
embodied self, has been dealt with extensively earlier. However, in relation to Mullins, it is worth considering her capacity to actually transform herself from fashion model to champion runner. It is important to remember at this point that questioning the constitution of the category normal does not just involve including within it those of us who are deficient, it also requires attention to categories of excess or excellence. Lennard Davis suggests that the disabled are deviants because they represent an extreme end of the curve. However, he does not go on to address the possibility that those identified as disabled might simultaneously occupy both ends of the curve at once. Aimee Mullins does this in that she is both disabled and a super-model, an amputee and a champion sprinter.

In the context of disability, technologies that add to or modify the body recast the idea of enhancement as enabling transgressive and subversive embodied possibilities rather than simply pushing normativist ableist ideology.

In Aimee Mullins' s case, it is unlikely on the basis of her enhanced disability (note it is not enhanced normativity) that it would be accepted that the little girl in the ad should have her legs removed and replaced with prostheses. The problem is that for the superabled disabled person, they still have no foothold in normativity. Rather they go from disability to super-ability without ever stopping at normal and therefore without being able to lay claim to that status.

It is worth recalling Scully and Rehmann-Sutter' s analysis of disabled 
embodiment as leading to an exclusion from the category of the 'naturally human' ${ }^{51}$ Here, however, the individual is simultaneously 'disabled' and enabled. ${ }^{52}$ Surprisingly, this does not seem to neutralise the categorisation of the individual as disabled but rather leads to their reclassification as unnaturally human and still therefore excluded from the normative humanity.

Wolbring argues that uses of enhancement technologies aimed at disability are in fact concerned with selecting for ability. The consequences of an 'ability selection or disability de-selection sentiment' in his view are that it will undermine a 'social justice view of disability.' He goes on:

And it will become the morally responsible way of acting. Where does the reality of this debate leave disabled people? Stuck with the medical/transhumanist model of disability. Where does it leave society? In an ability rat race. Ability to perform better. Ability to make more money. Ability to win commercial competitions... ${ }^{53}$

However, ability built on disability may not necessarily result in an upwards 'normative creep' as Wolbring suggests. He says if we take the transhumanist disability model:

the 'disabled' $(\mathrm{mM})$ of today will set the new norm (normative creep) after they were 'fixed' above the old norm (becoming the 
new 'non-disabled' (sM)) and the 'non-disabled' (sM) of today will be seen as the new 'disabled' $(\mathrm{mM}) .^{54}$

This may be, paradoxically, a far too utopian vision. If the effect of enhancement technologies is to rewrite the content of the normative categories, then the concern shifts away from the technologies themselves to the hierarchisation of the abled individuals to whom the technologies are applied. Indeed, it is clear that the norm as a form of average or 'species typical functioning' continues to persist. The flaw in Wolbring' s account is that individuals can only occupy one status or position in his typology at any one time whereas, in fact, to be both disabled and enhanced or 'superabled' at the same time seems to leave the normative untouched.

What we have been trying to do so far is challenge the standard upon which the idea of enhancement is meant to make sense. Disability, we have shown, is never just that. So, we come back to the question of enhancement but this time understood as containing within it everything we otherwise considered to be merely 'treatment or therapy' .

\section{IV.THE THERAPY/ENHANCEMENT DISTINCTION AS}

\section{A GUIDE TOREGULATORY DECISION-MAKING}

The aim of this discussion so far has been to examine the sustainability and efficacy, as a basis for ethical and medical decision-making, of a distinction between those alterations to humans that might be 
characterised as therapeutic and those that might be characterised as enhancement. In this part of the article, we turn our attention to the usefulness of this distinction for guiding legal limits. We focus on laws that regulate the use and availability of PGD. Legal regimes utilise the concept 'serious disability' as a benchmark for permissible embryo testing using PGD. In most of the legislative instruments regulating the use of PGD, 'serious disability' is not defined. Overall, while it may appear that the therapy/enhancement distinction has guided legal determinations about what to allow and what not to allow, a closer look at the legislation of three jurisdictions suggests both that it does not in fact do so and should not do so.

Regulations in Australia, Canada and the UK regarding the use and availability of PGD are currently undergoing intense scrutiny and development. PGD is used to detect embryos with genetic anomalies and to avoid their development. Typically, only those embryos that do not test positively for the specific genetic anomaly being investigated are considered suitable and selected for implantation in the woman' $\mathrm{s}$ uterus. Were the legislation to be relaxed and should the technology become refined it might be possible in the future to select embryos that tested positive for traits such as intelligence and athletic ability. Positioned outside of this continuum is what Karpin has coined 'negative enhancement' ${ }^{55}$ where a parent selects in favour of a trait commonly associated with a disability. In the context of in vitro fertilisation and assisted reproduction, as well as through the use of 
PGD, some individuals have sought to create and/or select embryos with certain traits that the majority of the community might consider undesirable such as deafness or dwarfism. ${ }^{56}$ This suggests that at some future time if it is possible legally and medically that selections may be made not only to achieve traits that the majority of the community perceives to be normal or better than normal but also to achieve traits a niche group perceives as desirable and 'normal' for them, though not typical. What then is the role of law and how should we determine where to draw the legal lines? ? $^{57}$

Canada has not yet promulgated regulations with respect to PGD. Canada' s Assisted Human Reproduction (AHR) Act prohibits a number of practices while establishing a regulatory framework for those reproductive practices that are permissible pursuant to license. With respect to the regulation of $\mathrm{PGD}$, the AHR Act prohibits sex selection except to prevent, treat or diagnose a sex-linked disease or disorder (section 5(e)). In addition, PGD will be governed by the AHR Act pursuant to those sections of the legislation and forthcoming regulations that deal with the collection, alteration, manipulation or treatment of any human reproductive material for the purpose of creating an embryo (sections 10(1) and 10(2)).

While PGD is being carried out in a limited way, and in a regulatory vacuum, in Canada, two publications of the Government of Canada have identified some of the policy debates raised by this issue. The first is a consultation document of the Health Canada Assisted Reproduction 
Office, Issues Related to the Regulation of Pre-Implantation Genetic Diagnosis Under the Assisted Human Reproduction Act $t^{58}$ and the second is a publication of the Canadian Biotechnology Secretariat, Brave New World: Where Biotechnology and Human Rights Intersect. ${ }^{59}$ In its consultation document, Health Canada distinguishes between the use of PGD for 'medical/health reasons' and its use for 'non-health related traits such as hair or eye colour'.$^{60}$ They cite the 'serious condition' standard as a limitation on the use of PGD about which there is some agreement, but acknowledge that it would be 'difficult to define' and that 'there are many complex factors that need to be accounted for in this definition' ${ }^{61}$ Moreover, as the Brave New World report points out, access to PGD in Canada "is currently controlled by the medical profession' ${ }^{62}$ Falling outside of formal regulation, decisions relating to $\mathrm{PGD}$ are privately made by the woman, or couple, with her doctor. ${ }^{63}$ Since there are no regulations or guidelines about what a 'serious' condition is, this determination falls to the clinicians involved. In Australia, therapeutic selection against serious disorders is not only allowed but facilitated by regulations and guidelines that allow the use of PGD to screen to avoid transmission of these conditions. At the federal level, the National Health and Medical Research Council's Ethical Guidelines on the Use of Assisted Reproductive Technology in Clinical Practice and Research (NHMRC ART) provide guidance on the circumstances in 
which it would be appropriate to use PGD. ${ }^{64} \mathrm{~A}$ number of the States have specific legislation governing assisted reproductive technology services. While these regulatory instruments do set up systems for the governance of the provision of PGD in those States, the NHMRC ART nevertheless applies to all States and Territories, because compliance with the guidelines is necessary for an IVF clinic to obtain accreditation. All IVF providers are required by the Reproductive Technology Accreditation Committee (RTAC) to comply with the guidelines. ${ }^{65}$ The NHMRC ART guidelines set down specific recommendations in regards to the provision of PGD. Clause 12.1 of the guidelines reads:

PGD is currently used to detect serious genetic conditions, to improve ART outcomes and, in rare circumstances, to select an embryo with compatible tissue for a sibling. These uses have profound ethical significance including:

- what counts as a serious genetic condition is controversial;

- there are different perceptions of disability;

- the practice of selecting against some forms of abnormality may threaten the status and equality of opportunity of people who have that form of abnormality;

- the procedures involve the disposal of some healthy embryos; and

- the procedures have technical limitations (such as the failure 
to identify the genetic abnormality of interest)

Clinics must ensure careful evaluation of these and all other relevant issues before the use of PGD. ${ }^{66}$

These guidelines complicate the idea of disability and the significance of its consequences. Moreover, they demonstrate how difficult it is to rely upon the therapy/enhancement distinction to sort out what should and should not be prohibited. The resort to the language of abnormality presupposes a highly contestable shared assumption about what is in fact normal.

Clause 12.2 of the guidelines recommends against allowing selection for prevention of conditions that do not seriously harm the person to be born; selection of the sex of an embryo except to reduce the risk of transmission of a serious genetic condition; or selection in favour of a genetic defect or disability in the person to be born. Clause 12.2 clearly relies on a shared understanding of disability that has been discounted in clause

12.1. Moreover, the application of a therapy/enhancement distinction is instantiated despite the category of disability itself having been critiqued in the previous clause.

ART Clinics too produce ethical guidelines. These documents provide a resource for understanding what counts as a disability in the clinical context. For instance, Sydney IVF' s guidelines ${ }^{67}$ clearly state that selection against traits not associated with disease and selection for disease or disability traits is regarded as inappropriate. While there is 
no specific statement regarding what might be a disability or disease trait, we get a clue from the statement below:

While there are genetically based traits that could be perceived as advantageous or disadvantageous, such advantage or disadvantage is likely to be circumstantial and unpredictable. Were it possible to use IVF with PGD to produce a child free of a familial trait that is not obviously associated with disease or disability, it would be unwise to do so to avoid an outcome that, with a level of parental respect and love that any child should be able to expect to receive, would not be a clinically important concern to the child. ${ }^{68}$

Sydney IVF makes the standard a disease or disability of 'clinical' , rather than social, importance. In these circumstances clinical can be understood to refer to those diseases or disabilities that would require treatment in the clinic. Since all of us require treatment in the clinic at some point, it is clear that what is being referred to here must be something more significant that minor ailments or indeed minor disabilities. Victoria, South Australia and Western Australia, each has a different set of criteria to determine when a disability is significant enough to allow it to be avoided via PGD. In all these States, the regulatory regime is vague and the best way to determine what is a disability significant enough to allow PGD is to work in reverse by looking at the conditions for which testing has been approved. ${ }^{69}$ These range from single-gene disorders (e.g. cystic fibrosis) or 
chromosomal disorders ${ }^{70}$ such as Trisomy 18, to 'Autosomal recessive conditions where it is proposed to identify and select against carrier embryos in addition to testing for the condition'.$^{71}$ The inclusion of carrier embryos is particularly significant because it further tests and questions the usefulness of the therapy/ enhancement distinction. Is it therapy to improve your child' s future reproductive potential by ensuring that they will not have to face an adverse reproductive decision when they decide to have children because they carry the gene for a disease or disability that may be passed on?

Selection in favour of a disability is prohibited whether by virtue of the policies of the State-specific regulatory bodies or by compliance with the NHMRC ART Guidelines. ${ }^{72}$ In Victoria, the Infertility Treatment Authority (ITA) has issued a policy on the use of PGD that includes a prohibition on the use of PGD for selection in favour of a disability. While Victorian legislation does not prohibit such a practice, the ITA considers 'selection in favour of genetic disease or abnormality' 'inconsistent' with the first guiding principle of the $\mathrm{Act}^{73}$ (that 'the welfare and interests of any person...to be born...are paramount' ). ${ }^{74}$ Furthermore, the compliance with the NHMRC ART Guidelines forms one of the licence conditions for ART centres, ${ }^{75}$ thereby excluding selection in favour of disability. In Western Australia, neither the legislation nor the Reproductive Technology Council' s policy on PGD explicitly contemplates the use of PGD for selection in favour of a disability. Nonetheless, a condition of every Western Australian licence 
is accreditation with the RTAC, which, in turn, requires compliance with the NHMRC ART Guidelines.

In the UK, PGD is regulated pursuant to the issuing of a license by the Human Fertilisation and Embryology Authority (HFEA). While the Human Fertilisation and Embryology Act 1990 (HFE Act) (unamended) does not explicitly address the issue of PGD, under its current Code of Practice ${ }^{76}$ the HFEA does provide guidance for the use of PGD and states:

The use of PGD should be considered only where there is a significant risk of a serious genetic condition being present in the embryo. The perception of the level of risk by those seeking treatment is an important factor in the decision making process. The seriousness of the condition should be a matter for discussion between the people seeking treatment and the clinical team (emphasis added). ${ }^{77}$

Section G12.3.3 of the Code of Practice lists the factors that should be considered in making the decision to screen for a particular disability:

(a) the view of the people seeking treatment of the condition to be avoided;

(b) their previous reproductive experience;

(c) the likely degree of suffering associated with the condition; and

(d) the availability of effective therapy, now and in the future; and

(e) the speed of degeneration in progressive disorders; and 
(f) the extent of any intellectual impairment; and

(g) the extent of social support available; and

(h) the family circumstances of the people seeking treatment. ${ }^{78}$

In this way the HFEA appears to encourage contextualisation, which raises again the argument that disability and co-extensively enhancement are fluid and unsustainable as meaningful criteria for determining the regulatory limits of the use of PGD. ${ }^{79}$

At the time of writing, a Bill has been presented to the UK Parliament, the Human Fertilisation and Embryology Bill 2007. Under this amending Bill, a new provision specifically dealing with genetic testing of embryos is to be inserted into Schedule 2 of the Act, paragraph 1ZA, which prohibits the testing of an embryo except in specified circumstances. Those cases are: where there is a particular risk that the embryo may have any gene, chromosome or mitochondrion abnormality, establishing whether it has that abnormality or any other gene, chromosome or mitochondrion abnormality; where the authority is satisfied that in 'relation to the abnormality of which there is a particular risk' , and 'any other abnormality for which testing is to be authorised under sub-paragraph (1)(b) that there is a significant risk that a person with the abnormality will have or develop a serious physical or mental disability, a serious illness or any other serious medical condition' . The current policy of the HFEA therefore appears to be preserved 
under the proposed amendments of the Bill - to test using PGD, there must be a significant risk of a serious physical/mental disability/illness/medical condition.

In addition, the proposed HFE amendments contain an explicit prohibition on the use of PGD to select in favour of a disability. Clause 14 of the HFE Bill proposes a new subsection 13(9), which prohibits 'preferring' those 'embryos... known to have a gene, chromosome or mitochondrion abnormality' above those 'not known to have such an abnormality' ${ }^{80}$ As the Explanatory Notes emphasise, this new licence condition prevents 'similar situations to cases, outside the UK, where positive selection of deaf donors in order deliberately to result in a deaf child have been reported' ${ }^{81}$

The legislative attempts to regulate the uses of PGD in Australia and the UK rely (in part) upon a concept of serious condition or disability as the condition precedent for authorising the use of genetic testing of the embryo. Implicit in this standard is a concern about curtailing the use of PGD to design or tailor the characteristics of one' s progeny, indeed to use PGD to screen for certain desired and desirable characteristics or traits. By confining the use of PGD to testing for serious conditions or disabilities, its status as a therapeutic technique is sought to be preserved. In this way, an ethical distinction between therapeutic and nontherapeutic selection (enhancement) has been written into the law by using 'serious disability' as the benchmark. However, the legislated use of the language of 'abnormality' in the UK and Australian legislation 
clearly suggests a stable and knowable norm against which these determinations can be made. As we have argued though, the concept of normal embodiment is unsustainable as both a material fact and normative goal. The prohibition of favouring an affected embryo, while not legislating directly with respect to enhancement, clearly posits a normative standard below which (rather than above which) it is not possible to 'design'. We conclude therefore by challenging the appropriateness of imposing a system of regulatory constraints such as those described above on these technologies which enable or constrain alteration by means of selection given their reliance on assumptions about the meaning of disability, abnormality and normalcy and the corelated reliance on an unsustainable distinction between therapy and enhancement to offer ethical, medical and regulatory limits. 


\section{END NOTES}

* Dr Isabel Karpin is a Senior Lecturer in the Faculty of Law, University of Sydney, and Roxanne Mykitiuk is an Associate Professor at Osgoode Hall Law School, York University. Research for this article was partly funded by a Canadian High Commission, Canadian Studies, Faculty Research Program Grant. Jo Sutton, Marta Iljadica, Stephanie Turnham and Mark Pioro provided excellent research assistance.

${ }^{1}$ C. Elliot, Better than Well: American Medicine Meets the American Dream (W.W. Norton 2003); M.J. Sandel, The Case Against Perfection: Ethics in the Age of Genetic Engineering (Belknap Press of Harvard University Press 2007); F. Fukuyama, Our Post Human Future: Consequences of the Biotech- nology Revolution (Farrar, Straus and Giroux 2002).

2 M.J. Sandel, supra n.2; see also, M.H. Shapiro, 'Does Technological Enhancement of Human Traits Threaten Human Equality and Democracy?' (2002) 39 San Diego Law Review 769; E.T. Juengst, R.H. Binstock, M. Mehlman, S.G. Post and P. Whitehouse, 'Biogerontology, 'Anti-aging Medicine,' and the Challenges of Human Enhancement' (2003) 33 The Hastings Center Report 4, to name just a few. Jackie Leach Scully and Christoph Rehmann- Sutter have argued that we need to do away with the language of enhancement altogether: J.L. Scully and C. Rehmann-Sutter,

'When Norms Normalize: The Case of Genetic “Enhancement” ' (2001) 12 Human Gene Therapy 1. We will return to discuss this argument in detail below.

${ }^{3}$ M. Shildrick, 'Unreformed Bodies: Normative Anxiety and the Denial of Pleasure' (2005) 34 Women's Studies 327 at 327.

${ }^{4}$ M. Shildrick, Embodying the Monster: Encounters with the Vulnerable Self (Sage 2002) at 4.

${ }^{5}$ For a related critique of normalcy in relation to embodiment and voluntary amputation. See MacKenzie 'Somatechnics of Medico-Legal Taxonomies: Elective Amputation and Transableism' (this volume).

${ }^{6}$ The President' s Council on Bioethics, Beyond Therapy: Biotechnology and the Pursuit of Happiness, A Report of the President's Council on Bioethics (DANA Press 2003), http://www.bioethics.gov/reports/beyondtherapy (accessed on 30 May 2007). A number of other jurisdictions have also considered the issue of enhancement within the context of the regulation of reproductive technology including the United Kingdom; Human Genetics Commission, Making Babies: Reproductive Decisions and Genetic Technologies (Human Genetics Commission 2006), Human Genetics Commission http://www.hgc.gov.uk/UploadDocs/DocPub/Document/Making\%20Babies\% 20Report\%20-\%20final\%20pdf.pdf (accessed on 4 February 2008); Human Genetics Commission, Choosing the Future: Genetics and Reproductive Decision Making (Human Genetics Commission 2004), Human Genetics Commission http://www.hgc.gov.uk/UploadDocs/DocPub/Document/ChooseFuturefull.pdf (accessed on 4 February 2008); Canada: Canadian Biotechnology Secretariat, Brave New World: Where Biotechnology and Human Rights Intersect (Government of Canada 2005), Biostrategy http://biostrategy.gc.ca/HumanRights/HumanRightsE/Biotech_Intro_E.pdf (accessed on 4 February 2008), and New Zealand: Human Genome Research Project, Choos- 
ing Genes for Future Children (Human Genome Research Project 2006), University of Otago http://www.otago.ac.nz/law/genome/resources/Genome Teaser_06.pdf (accessed on 4 February 2008).

7 The President' s Council on Bioethics, ibid. at 13.

${ }^{8}$ Ibid.

${ }^{9}$ Ibid. at $13-14$.

${ }^{10}$ See e.g. N. Daniels, Just Health Care (Cambridge 1985) at 42; A.

Buchanan, D.W. Brock, N. Daniels and D. Wikler, From Chance to Choice: Genetics and Justice (Cambridge University Press 2000) at 24; C. Boorse, 'On the Distinction Between Disease and Illness' (1975) 5 Philosophy and Public Affairs 1; C. Boorse, 'Health as a Theoretical Concept' (1977) 44

Philosophy of Science 4. For a more considered discussion of species-typical normal func- tioning, see K. Taylor and R. Mykitiuk, 'Genetics, Normalcy and Disability’ (2000) 2 ISUMA: Canadian Journal of Policy Research 3 at 67 and J.L. Scully and C. Rehmann-Sutter, supra n.2 at 91.

11 The President' s Council on Bioethics, supra n.6 at 16.

${ }^{12}$ For a critique of the regulation of cosmetic surgery in England and Wales. See Latham 'The Shape of Things to Come: Feminism, Regulation and Cosmetic Surgery' (this volume).

${ }^{13}$ K. Taylor and R. Mykitiuk, supra n.10 at 66.

14 O. Bogdashina, Sensory Perceptual Issues in Autism and Asperger Syndrome: Different Sensory Experiences, Different Perceptual Worlds (Jessica Kingsley Publishers 2003).

15 J.L. Scully and C. Rehmann-Sutter, supra n.2 at 92.

16 G. Gillingham, 'Autism: Disability or Super-ability? Designing a Therapy based on Experiences and Feelings as Described by Individuals with Autism' in Collected Papers: Therapeutic Approaches to Autism: Research and Practice (Sunderland 1991). Also see our discussion of Aimee Mullins and Oscar Pistorius in Section III.

${ }^{17}$ We rely on Margrit Shildrick' s use of the 'term anomalous embodiment' : Shildrick, 'Transgressing the Law with Foucault and Derrida: Some Reflection on Anomalous Embodiment' (2005) 47 Critical Quarterly 3.

18 G. Wolbring, NBIC, NGO's and the Three Types of Disabled People, paper written for the Conference Within and Beyond the Limit of Human Nature, 12 - 16 October 2003 Berlin, Germany, version from 21 September 2003, online: International Center for Bioethics, Culture and Disability, http:// www.bioethicsanddisability.org/boell.html (accessed on 30 May 2007).

19 See N. Bostrom, Transhumanist Values. http://www.transhumanism.org/ index.php/WTA/more/transhumanist-values/ (accessed on 17 January 2008).

${ }^{20}$ Ibid.

21 Ibid.

22 D.T. Mitchell and S.L. Snyder, Narrative Prosthesis: Disability and the Dependencies of Discourse (University of Michigan Press 2000) at 6.

${ }^{23}$ See ibid. at $6-7$.

${ }^{24}$ L.J. Davis, Bending Over Backwards: Disability, Dismodernism and Other Difficult Positions (New York University Press 2002) at 241.

25 D. Wills, Prosthesis (Stanford University Press 1995) at 141. 
${ }^{26}$ M. Shildrick, supra n.3 at 327.

27 Ibid.

${ }^{28}$ Ibid.

${ }^{29}$ Supran.24.

${ }^{30}$ G. Wolbring, supra n.18.

${ }^{31}$ See supra n.19. Several authors have engaged critically with transhumanism. See e.g. N. Badmington, ‘Theorizing Posthumanism' (2003) 53 Cultural Critique 10; E. Thacker, 'Data Made Flesh: Biotechnology and the Discourse of the Posthuman' (2003) 53 Cultural Critique 72 - 97. Winter; N.K. Hayles, 'Afterword: The Human in the Posthuman' (2003) 53 Cultural Critique 134.

32 James Martin, in J. Martin, The Meaning of the 21st Century: a Vital Blueprint for Ensuring Our Future (Riverhead Books 2006) at 198, argues that 'bioconvergence' (the convergence of biological and non-biological pro- cesses) will allow individuals to, amongst other things, enhance their senses.

${ }^{33}$ R. Garland-Thompson, 'Integrating Disability, Transforming Feminist Theory' (2002) 14 National Women's Studies Association Journal 3 at 10.

34 Ibid. at 5.

${ }^{35}$ Ibid.

36 Ibid. at 1.

37 M. Smith, 'The Vulnerable Articulate: James Gillingham, Aimee Mullins, and Matthew Barney' in M. Smith and J. Morra (eds), The Prosthetic Impulse: From a Posthuman Present to a Biocultural Future (MIT Press 2006) 43 at 58.

${ }^{38}$ Ibid.

${ }^{39}$ V. Sobchack, 'A Leg to Stand on: Prosthetics, Metaphor and Materiality' in The Prosthetic Impulse: From a Posthuman Present to a Biocultural Future (MIT Press 2006) 17. See also supra n.37.

40 Ibid. at 38.

${ }^{41}$ Supran.33 at 6.

42 Fashion designer Lazaro Hernandez of Proenza Schouler told Teen Vogue in February 2006 that, 'She looked like no one else at the time. She was this alien, and fashion is always looking for newness'. 'Who' $\mathrm{s}$ that Girl?' (2006) Teen Vogue, February.

43 L.J. Davis, 'Constructing Normalcy: The Bell Curve, the Novel, and the Invention of the Disabled Body in the Nineteenth Century' in L.J. Davis (ed.), The Disability Studies Reader (Routledge 1997) at 9.

44 R.E. Ashcroft, 'American Biofutures: Ideology and Utopia in the Fukuyama/Stock Debate’ (2003) 29 Journal of Medical Ethics 59 at 61.

45 J. Longman, 'An Amputee Sprinter: Is He Disabled or Too-Abled?' (2007) New York Times, 15 May.

${ }^{46}$ International Association of Athletics Federations Competition Rules 2008, Rule 144, http://www.iaaf.org/ (accessed on 17 January 2008).

${ }^{47}$ Indeed, on 14 January 2008, the International Association of Athletics Federations ruled that Pistorius' s prosthetics were 'technical aids' and he was therefore ineligible to compete at the Beijing Olympics: J. Robinson,

'Ruling Halts Amputee Sprinter' s Olympic Bid' (2008) New York Times, 15 January.

48 J. Robinson and A. Schwarz, 'Olympic Dream Stays Alive on Synthetic 
Legs' (2008) New York Times, 17 May.

${ }^{49}$ See e.g. S.A. Sherwood, 'Don' t Hate Me Because I' m Beautiful.. .And Intelligent.. .And Athletic: Constitutional Issues in Genetic Enhancement and the Appropriate Legal Analysis' (2001) 11 Health Matrix 633.

50 For a discussion of the characterisation of such techniques as enhancement, see N.M.P. King and R. Robeson, 'Athlete or Guinea Pig? Sports and Enhancement Research' (2007) 1 Studies in Ethics, Law and Technology 1, http://www.bepress.com/selt/vol1/iss1/art1 (accessed on 5 February 2008).

51 Supran. 2 at 92.

${ }^{52}$ Here, we might have used the word enhanced but that begs the question.

${ }^{53}$ G. Wolbring,supra n.18.

54 Ibid.

55 I. Karpin, 'Choosing Disability: Preimplantation Genetic Diagnosis and Negative Enhancement' (2007) 15 Journal of Law and Medicine 80.

56 Ibid. See also S. Baurch, D. Kaufman and K. Hudson, 'Genetic Testing of Embryos: Practices and Perspectives of US IVF Clinics' (2006) Fertility $\begin{array}{lllll}\text { and Sterility } & \text { 89: } & 1053 \quad & - & 1058 .\end{array}$ http://www.dnapolicy.org/resources/GeneticTestingofEmbryos.pdf (accessed on 20 January 2008).

57 For a critique of arguments which justify sex selection for 'family balancing' purposes. See Wilkinson 'Sexism, Sex Selection, and 'Family Balancing' ' (this volume).

${ }^{58}$ Health Canada, Issues Related to the Regulation of Pre-implantation Genetic Diagnosis under the Assisted Human Reproduction Act (Health Canada 2006), http://www.hc-sc.gc.ca/ahc-asc/alt_formats/ccsscm/pdf/pgd_e.pdf (accessed on 28 May 2008).

${ }^{59}$ Canadian Biotechnology Secretariat, supra n.6.

${ }^{60}$ Supran.58 at 11.

61 Ibid.

${ }^{62}$ Canadian Biotechnology Secretariat, supra n.6 at para. 3.1.

${ }^{63}$ Ibid.

${ }^{64}$ See National Health and Medical Research Council, Ethical Guidelines on the Use of Assisted Reproductive Technology in Clinical Practice and Research, 2004 as Revised in 2007 to Take into Account the Changes in Legislation (Australian Government 2007), http://www.nhmrc.gov.au/publi- cations/synopses/_files/e78.pdf (accessed on 20 January 2008) at para. 12.

${ }^{65}$ See s.11 of the Research Involving Human Embryos Act 2002 (RIHE). Fur- thermore, ART-specific State regimes also mandate, directly or indirectly, compliance with the NHMRC ART Guidelines: for Victoria, see Infertility Treatment Authority, Conditions for Licence: Clinics, Hospitals and Day Procedure Centres (Infertility Treatment Authority 2006), s.2 ( para. 1.3). For South Australia, see Reproductive Technology (Code of Ethical Clinical Practice) Regulations 1995 (SA). For Western Australia, see Sch, s.2A. See Human Reproductive Technology Act 1991 (WA) ss.33(2)(ea) and 29(5)(aa).

66 Supra n.64.

67 Sydney IVF, Ethical Guidelines: Respect for Future Persons When 
Procreating with IVF and Preimplantation Genetic Testing or Diagnosis for Other than Preventing the Transmission of Serious Disease or Disability (Sydney IVF 2007) on file with the authors.

68 Ibid. at 10.

${ }^{69}$ For a detailed description of the diseases for which PGD has been permitted in each of the States, see supra n.56.

70 The South Australian Council on Reproductive Technology (SACRT) has taken the requirement for a genetic defect to refer to "a single gene or chromosome disorder the likely effect of which is to seriously impair a person who inherits the disorder from one or both parents' : South Australian Council on Reproductive Technology, 'Memorandum 12: Preimplantation Genetic Diagnosis (PGD) - Definition of 'A Genetic Defect' for the purpose of Determining Eligibility of Treatment (revised October 2006)' in Annual Report 2004, http://www.dh.sa.gov.au/reproductivetechnology/documents/archive/Annual-Reports/AnnualReportfor2004.pdf (accessed on 5 February 2008) at 39.

${ }^{71}$ Infertility Treatment Authority, Approved Genetic Testing (September 2007), http://www.ita.org.au/www/257/1001127/displayarticle/1001217.html (accessed on 4 February 2008).

72 Supra n.64.

${ }^{73}$ Infertility Treatment Authority, Genetic Testing and the Requirements of the Infertility Treatment Act 1995: Policy in Relation to the Use of Preimplanta- tion Genetic Diagnosis (PGD) (April 2006).

${ }^{74}$ Infertility Treatment Act 1995 (VIC), s.5(1)(a).

75 Supran.64.

76 Human Fertilisation and Embryology Authority, Code of Practice (HFEA 2007), http://cop.hfea.gov.uk/cop/pdf/COPv2.pdf (accessed on 28 May 2008) at G.12.3.2.

${ }^{77}$ Ibid.

78 Ibid.

${ }^{79}$ Ibid. at para. G. 12.3.1: '[the] decision to use PGD should be made in con- sideration of the unique circumstances of those seeking treatment, rather than the fact that they carry a particular genetic condition' .

80 The Human Fertilisation and Embryology Bill (29 January 2008 version [HL Bill 25]) prohibits selection in favour of a disability. See clause 14.

${ }^{81}$ Explanatory Notes, Human Fertilisation and Embryology Bill 2007 [HL] at para. 109. The Explanatory Note refers to the Bill introduced in the House of Lords on 8 November 2007 [HL Bill 6]; however, the provisions discussed here were not amended in the current version of the Bill and therefore at the time of writing the comments made are still applicable. 